\title{
Full-Range Leadership as a Predictor of Extra Effort in Online Higher Education: The Mediating Effect of Job Satisfaction
}

\author{
Donald E. Barnett, Ed.D. \\ Grand Canyon University
}

\begin{abstract}
Online higher education has rapidly expanded in the United States and displays a great opportunity for growth. Coupled with the growth of e-learning is the need for adjunct faculty to satisfy the need for additional online classes. Despite the importance of online adjunct faculty, little research has been performed to determine their work experiences. This quantitative, correlational study investigated the predictive relationship between the perceived use of transformational, transactional, and laissez-faire leadership behaviors on the extra effort of adjunct faculty who facilitate online classes at a for-profit university in the United States. In a further investigation, the researcher investigated the variable of job satisfaction to determine if it mediated the relationship between leadership style and extra effort. The researcher used the Multifactor Leadership Questionnaire and Spector's Job Satisfaction survey to collect data used in inferential analysis. The researcher performed a stepwise multiple regression and a Baron and Kenny mediation analysis to answer the research questions. The results showed perceived transformational leadership behaviors displayed a statistically significant positive predictive relationship with extra effort, and job satisfaction was a partial mediator between the relationship of transformational leadership and extra effort. The results suggest transformational leadership is beneficial to the extra effort put forth by the sample of adjunct faculty who teach online classes.
\end{abstract}

\section{Introduction}

The workforce in higher education has shifted over the past few decades. At one time, the faculty of institutions of higher education were primarily tenured or tenure-track. Presently, faculty in United States post-secondary education are primarily adjunct, non-tenure-track, instructors (Eagan, Jaeger, \& Grantham, 2015). Kezar (2012) observed that $75 \%$ of all new hires at universities in the United States were part-time, adjunct faculty, and this number is steadily increasing (Gilpin, Saunders, \& Stoddard, 2015). The increased use of adjunct faculty coincides with an increase of online class offerings. In the United States, enrollment in online classes exceeded 5.8 million students in 2014, with 2.85 million students enrolled exclusively in online courses (Allen \& Seaman, 2016). The increased demand for online education has exceeded the capabilities of full time, tenured faculty (Caruth \& Caruth, 2013), and increased the demand for adjunct faculty to facilitate online offerings.

Despite the increased employment of adjunct faculty to facilitate online courses, there is a lack of research investigating online adjunct effectiveness (Datray, Saxon, \& Martirosyan, 2014). Moreover, there is a specific lack of research on the job satisfaction of adjunct, and particularly adjunct faculty who teach online courses (Rich, 2015). Currently, there is a dearth of research investigating the outcomes of perceived administrative leadership on online adjunct faculty extra effort. This lack of research is notable because online adjuncts are relatively new to higher 
education. Understanding their work experiences may provide information that can be used to design leadership development programs for university administrators. The purpose of this paper is to address this gap in knowledge and investigate the predictive relationship between the administrative use of Full-Range Leadership, as perceived by adjunct faculty who facilitate online courses, and the perceived extra effort offered by the same online adjunct faculty. Additionally, the researcher investigated the mediating relationship of job satisfaction on any perceived overall leadership style that displayed a predictive relationship with online adjunct faculty extra effort.

Adjunct faculty members, despite their importance, typically do not receive adequate support from university administrators (Kezar, 2013a). A typical adjunct has inadequate opportunities for advancement, and seldom receives an increase in salary. Universities generally do not offer health insurance to adjunct faculty, and retirement benefits are extremely limited. Additionally, adjuncts seldom have influence in university policy. Universities employ adjuncts at a considerable cost savings because they are remunerated at roughly one-third the salary of tenured, or tenure-track, faculty (Halcrow \& Olson, 2008; Kezar, 2013b; Morton, 2012). Irrespective of the increasing importance of adjunct faculty, universities typically do not nurture adjuncts in the same manner as tenure-track faculty. Generally, adjuncts are detached from their full-time counterparts (Webb, Wong, \& Hubbal, 2013; Dailey-Hebert, Mandernach, DonnelliSallee, \& Norris, 2014; Ott \& Cisneros, 2015), their university, and department (Benton \& Li, 2015). Adjuncts who teach online classes especially experience this disconnect, (Benton \& $\mathrm{Li}$, 2015), and adjunct faculty typically depend on other adjunct members of faculty for encouragement (Rich, 2015). Given these circumstances, it is important to discover what perceived leadership behaviors encourage online adjunct faculty members to go beyond expectations and give extra effort in the performance of their job duties.

\section{Literature Review}

The theoretical foundation for this research was the Full-Range Leadership Model (FRLM). The FRLM is comprised of three distinct styles of leadership: transformational leadership, transactional leadership, and laissez-faire leadership. Each of these styles of leadership is divided into individual dimensions, which allows for a thorough investigation of most behaviors demonstrated by leaders (Avolio \& Bass, 2004). Researchers have used the FRLM extensively in the exploration of perceived leadership behaviors in organizations, and it is one of the best-conceived and most validated leadership models.

Transformational Leadership. Transformational leadership encourages "performance beyond expectations" from subordinates (Bass, 1985). Bass (1985), who expanded on the work of Burns (1978), stated transformational leadership increases subordinate motivation and willingness to exceed expectations by addressing follower needs and fostering the values and ideals of the leader and organization. Consequently, followers strive to exceed expectations and give extra effort in the performance of their duties. Transformational leaders go beyond satisfying the basic needs of their followers by awakening and fulfilling their subordinates' higher order needs, which encourages and arouses individuals to achieve their highest potential (Burns, 1978). 
Perceived transformational leadership behaviors have demonstrated a positive relationship with employee performance (Thamrin, 2012), and enhancing the job satisfaction of university faculty in online for-profit and traditional public universities in the United States (Barnett, 2017; Bateh \& Heyliger, 2014). Avolio and Bass (2004), in their modification of the FLRM, divided transformational leadership into five dimensions.

Idealized influence. A leader's demonstration of high ethical and moral standards exemplifies idealized influence. Leaders who are perceived as using idealized influence do not seek personal gain (Northouse, 2013), and are a focus of imitation and respect from their subordinates (Bass \& Riggio, 2006). Bass and Avolio (1994) suggested followers might desire to emulate their leaders and identify with them because of a leader's perceived dedication to ethical and moral conduct. Stadelmann (2010) found idealized influence was a significant predictor of follower extra effort. Avolio and Bass (2004) separated idealized influence into two distinct behaviors: behavioral and attributed, with behavioral denoting how followers perceive the leader's ethical and moral behaviors, and attributed denoting the overall perceptions of the leader's ability to lead.

Inspirational motivation. Leaders use inspirational motivation by effectively communicating high expectations. They motivate and inspire subordinates by demonstrating enthusiasm and optimism about the organization's future (Northouse, 2013). Leaders convey a promising vision of the future and motivate their followers to be dedicated to the vision of the organization (Avolio \& Bass, 2004). Inspirational communication is a primary aspect of inspirational motivation (Avolio, Bass, \& Jung, 1999).

Intellectual stimulation. Intellectual stimulation consists of encouraging subordinates to exhibit innovative behaviors, express creativity, and do their utmost to exhibit performance that exceeds expectations (Northouse, 2013). Leaders provide challenging assignments and encourage problem solving to formulate new ways of thinking. Leaders never criticize their subordinate's ideas. Rather, they encourage independent thought and creative approaches that facilitate the innovation in the completion of job tasks (Avolio \& Bass, 2004).

Individualized consideration. A leader acts as a mentor and coach to develop their followers to their fullest ability. Leaders who exhibit individualized consideration actively and effectively listen to their followers, express encouragement, frequently interact with their subordinates, and offer emotional and social support when needed (Northouse, 2013). Balyer (2012) observed individualized consideration is a behavior that makes a follower feel unique and appreciated.

Transactional Leadership. Burns (1978), inspired by the 1947 work of Max Weber, initially formed the Transactional Leadership Theory. Transactional leaders use praises, rewards, and promises that promote self-interest to motivate their followers to achieve organizational goals (Burns, 1978). Leadership strictly defines all job duties, benefits are clearly stated, and disciplinary codes are strictly enforced (Bass \& Avolio, 1994). Transactional leadership is 
composed of three dimensions: contingent rewards, management-by-exception (active), and management-by-exception (passive). Avolio and Bass (2004) later moved management-byexception (passive) to laissez-faire leadership for measuring leadership perceptions with the Multifactor Leadership Questionnaire.

Contingent reward. As the name implies, contingent reward is based on exchanges, or agreements, between leader and follower that denote rewards for accomplishing the agreed upon work, and punishments for substandard performance (Bass \& Riggio, 2006). Contingent reward is derived from an agreement between two individuals, or parties, that sets forth a contract that designates an exchange of currency, or other item of value, for a specific action (Burns, 1978). Contingent reward largely uses self-interest as a method of motivation, and leadership clearly communicates all individual goals and organizational expectations to the employee (Bass, 1997). Bass (1985) observed contingent rewards foster follower confidence and reinforce performance expectations.

Management-by-exception (active). Bass (1997) maintained leaders who practice management-by-exception (active) inform their followers of all organizational policies and goals, and communicate clear individual expectations. Leaders actively monitor their employees work, and take appropriate action before there is a violation of company policy or deterioration in the quality of the work. Managers pay close attention to employee performance and are quick to take corrective action when needed.

Management-by-exception (passive). Bass (1997) observed management-by-exception (passive) differs from the active form because the leader only makes a curative action after a problem occurs or an employee's work becomes substandard. Managers typically use negative reinforcements, such as negative feedback, criticism, punishment, or some other form of correction in this dimension of leadership (Northouse, 2013). As noted earlier, Avolio and Bass (2004) changed management-by-exception (passive) to a dimension of laissez-faire leadership for measuring leadership perceptions.

Laissez-faire Leadership. Bass and Riggio (2006) stated laissez-faire leadership, in the managerial context, involves the absence and avoidance of any form of leadership. Laissez-faire leadership differs from management-by-exception (passive) in several ways. A laissez-faire leader does not act when a correction is required. They do not provide necessary feedback, offer aid, or develop their followers in any way (Northouse, 2013). Laissez-faire leaders avoid acting and shirk responsibility. They are inactive, indifferent, uninfluential, inattentive, and absent when their presence is required by their followers (Bass, 1990). Laissez-faire leadership behaviors are still perceived in some managers (Bateh \& Heyliger, 2014), but seldom observed in entire organizations (Bass, 1990).

Extra Effort. Seltzer and Bass (1990) observed extra effort entails employee behaviors that benefit the organization, which go beyond one's normal job expectations. Locke, Shaw, Saari, and Latham (1981) asserted extra effort represented an individual's inner willingness to devote extra energy and time to achieving the goals of the organization. Similarly, Morris (2009) defined extra effort to be when an employee voluntary gives effort, intensity, and time that goes beyond expectations. Avolio and Bass (2004) stated extra effort involved the leader's capability 
to inspire their followers to try harder, surpass management expectations, and foster their aspiration to succeed. Bass (1990) stated individuals would give extra effort for leaders who exhibit transformational leadership behaviors. Transactional leadership and passive management-by-exception, according to Bass (1990), are less effective in encouraging extra effort on the part of subordinates. In agreement with Bass, Stadelmann (2010) found transformational leadership was a significant predictor of follower extra effort.

Extra Effort and Job Satisfaction. Several theories have been set forth to explain extra effort. The expectancy theory (Vroom, 1964) stated individuals expend effort in proportion to the rewards they expect to receive. Moreover, the expectancy theory states leaders must attempt to understand their employees' "valence of possible outcomes and his expectancies regarding the consequences of different levels of effort for attaining them" (p. 192). Herzberg's Motivator/Hygiene Theory recognized extrinsic motivators are inclined to promote greater job satisfaction, which in turns leads to an individual exerting extra effort. Likewise, the Reciprocity Theory (Batemen \& Organ, 1983) and Social Exchange Theory (Konovsky \& Pugh, 1994) suggested individuals who exhibit high levels of job satisfaction will perform better than employees with lower levels of job satisfaction.

Philbin (1997) discovered evidence suggesting job satisfaction is an important reason why individuals put forth extra effort in their jobs. Trofino (2003) found increases in job satisfaction led to increases in extra effort. In the educational context. Nguni, Sleegers, and Denessen (2006) discovered high levels of job satisfaction in teachers resulted in extra effort in helping their students. Given the theoretical and empirical evidence, it is prudent to conclude job satisfaction plays a significant role in extra effort.

\section{Research Questions}

Previous research has shown positive relationships between the perceived use of transformational leadership behaviors and employee extra effort (Stadelmann, 2010). Bass (1990) determined transformational leaders were effective in fostering employee extra effort. Avolio and Bass (2004) noted contingent reward, a dimension of transactional leadership, was associated with the exchange of rewards for extra effort. Similarly, Vroom (1964) observed individuals tend to expend effort in relation to the expected reward for their effort, which suggests transactional leadership might have a positive relationship to employee extra effort. Laissez-faire leadership, particularly passive management-by-exception, is generally ineffective in promoting extra effort (Bass, 1990). The reciprocity and social exchange theories observed that job satisfaction is an important variable in increased job satisfaction. Based on these observations, and the previous discussions regarding the dimensions of full-range leadership and employee extra effort, the study proposes the research questions and null hypotheses listed below:

RQ1: To what extent does the administrators' transformational, transactional, and laissezfaire leadership style, as perceived by the online adjunct faculty who report to them, predict the extra effort of the same faculty?

$\mathrm{H}_{1}$ : There is no statistically significant predictive relationship between the administrator's transformational leadership style and extra effort. 
$\mathrm{H} 2_{0}$ : There is no statistically significant predictive relationship between the administrator's transactional leadership style and extra effort.

$\mathrm{H} 3_{0}$ : There is no statistically significant predictive relationship between the administrator's laissez-faire leadership style and extra effort.

RQ2: Does overall job satisfaction mediate the relationship between any overall leadership style that displayed a predictive relationship with extra effort in this study and extra effort?

$\mathrm{H} 4_{0}$ : Overall job satisfaction does not mediate the relationship between any overall style of leadership that displayed a positive relationship with extra effort in this study and extra effort.

\section{Method}

Design. To determine if administrative leadership behaviors were related to the extra effort of adjunct faculty who teach online classes, the researcher used a Pearson's correlation to determine if there was a correlation between perceived overall transformational, transactional, and laissez-faire leadership behaviors and online adjunct faculty extra effort. Next, the researcher performed stepwise multiple linear regressions with overall transformational, transactional, and laissez-faire leadership as the predictor variables and extra effort as the criterion variable to determine if there was any significant predictive relationship between variables.

Finally, the researcher conducted a Baron and Kenny mediation analysis to assess if overall job satisfaction mediated the relationship between any predictive overall leadership style and extra effort. The researcher performed three regressions to determine whether the data supported mediating relationship. Four criteria must be met for mediation to be established,: 1) the independent variable must display a relationship to the dependent variable, 2) the independent variable must be related to the mediator variable, 3 ) the mediator variable must show a relationship to the dependent variable while in the presence of the independent variable, and 4) the independent variable must cease to be a significant predictor of the dependent variable in the presence of the mediator variable (Baron \& Kenny, 1986).

Population. The sample for this study was taken from a population of approximately 800 adjunct faculty members at a large for-profit university in the Midwest United States. After Institutional Review Board (IRB) approval from the research site, the population was sent an email that invited participation in the study provided they had taught an online class within the past six months. The invitation gave directions to access the survey, which was hosted on an online survey site. Of the 800 adjuncts, 85 individuals responded to the survey invitation. Out of the 85 respondents, 77 completed the survey in its entirety. Given the large size of the university, anonymity concerns, and the fact that this research did not target a specific department within the university, it is impossible to know how many leaders were rated, or if more than one respondent rated an individual supervisor. 
Instruments. The Multifactor Leadership Questionnaire 5x short (MLQ) (Avolio \& Bass, 2004) was used to collect data on perceived leadership behaviors and extra effort. The MLQ measured the nine dimensions of the FRLM and extra effort using 39 questions measured on a 5-point Likert-type scale. The MLQ used four questions each to measure perceptions of the nine dimensions of the FRLM: inspirational motivation, intellectual stimulation, idealized influence (attributed), idealized influence (behavioral), individual consideration, contingent reward, management-by-exception (active), management-by-exception (passive), and laissezfaire. The MLQ also measured extra effort using three questions. To measure overall perceptions of transformational, transactional, and laissez-faire leadership, the individual dimensions of each leadership style were combined to create a higher order construct, as suggested by Bass, Avolio, Jung, and Berson (2003). Spector's Job Satisfaction Survey (JSS) (Spector, 1997) was used to collect data on overall job satisfaction. The JSS used 36 questions to measure nine dimensions of job satisfaction on a 6-point Likert-type scale. The job factors measured included perceptions of the nature of work, communication, operating procedures, coworker relationships, fringe benefits, contingent rewards, supervision, pay, and promotion potential. Per Spector (1997), the researcher summed the totals of all the individual dimensions to create a higher order construct to measure overall job satisfaction.

Validity. Per George and Mallery (2012), a Cronbach's alpha value of 0.90 or more is considered excellent, 0.80-0.89 is deemed good, 0.70-0.79 is regard as satisfactory, 0.60-0.69 is considered questionable, $0.50-0.59$ is poor, and below 0.50 is unacceptable. For this study, all constructs were deemed acceptable (Table 1).

\section{Data Analysis}

Demographic questions were not used in this study. Instead, the researcher produced the following table that displays the means, standard deviations, and Cronbach's alpha for the populations perceptions of their direct superior's use of transformational leadership, transactional leadership, and laissez-faire leadership, and their own extra effort, and overall job satisfaction (Table 1). Significant findings from an analysis of the data showed the sample perceived transactional leadership as the most used style of leadership $(M=2.87)$, followed by transformational leadership $(M=2.85)$, and laissez-faire leadership $(M=2.79)$. Avolio and Bass (2004) observed that for a variable to be viewed as used extensively, the mean should surpass $M$ =3, which none of the variables measured by the MLQ achieved. Per Spector (1997) a mean value of 116.34 indicated ambivalence towards job satisfaction; neither satisfied nor dissatisfied.

Table 1.

\begin{tabular}{llll}
\multicolumn{4}{l}{ Measures of Central Tendency and Cronbach's Coefficient Alpha $(\mathrm{N}=77)$} \\
\hline Leadership Style & $M$ & $S D$ & $\alpha$ \\
\hline Transformational leadership & 2.85 & 0.84 & 0.95 \\
Transactional leadership & 2.87 & 0.65 & 0.69 \\
Laissez-faire leadership & 2.79 & 0.77 & 0.79 \\
Overall job satisfaction & 116.34 & 19.92 & 0.90 \\
Extra effort & 2.90 & 1.00 & 0.78 \\
\hline
\end{tabular}

Note. $M=$ Mean; $S D=$ Standard Deviation 
The researcher performed a Pearson's correlation to discover if there was a correlation between extra effort and perceived overall transformational, transactional, and laissez-faire leadership (Table 2). Based on the results of the study, transformational leadership is related to extra effort $(r=.59, p<.01)$. Transactional leadership is related to extra effort $(r=0.37, p<$ 0.01). Laissez-faire leadership is related to extra effort $(r=-0.45, p<.01)$.

Table 2.

\begin{tabular}{llll} 
Pearson's Correlation with Four Variables & \\
\hline Variable & 1 & 2 & 3 \\
\hline Extra effort & --- & --- & --- \\
Transformational leadership & $0.59^{* *}$ & --- & --- \\
Transactional leadership & $0.37^{* *}$ & $0.44^{* *}$ & --- \\
Laissez-faire leadership & $-0.45^{* *}$ & $-0.65^{* *}$ & $-0.23^{*}$ \\
\hline
\end{tabular}

$* \quad p<.01$

$* * p<.05$

In an examination of the predictive relationship between perceived overall leadership behaviors and extra effort, a stepwise multiple linear regression was calculated to predict extra effort based on the independent variables transformational leadership, transactional leadership, and laissez-faire leadership (Table 3). A significant regression was found $(\mathrm{F}(1,75)=39.74, p<$ .001 ), with an $r^{2}$ of 0.35 . The adjusted r-square value of 0.34 indicated approximately $34 \%$ of the variability in the dependent variable of extra effort was predicted by the three independent variables in the model. Participants' predicted extra effort was equal to $0.90-0.14$ (Transformational Leadership). The squared semi-partial correlation for the predictor of transactional leadership, 0.35 , indicated approximately $35 \%$ of unique variance on the outcome of extra effort could be attributed to the transformational leadership variable. Extra effort increased 0.14 points for every 1 -point increase in transformational leadership. Transformational leadership was the only significant predictor of extra effort $(\beta=0.59, p<0.01)$. This suggests increases in transformational leadership are associated with increases in extra effort.

Table 3.

Stepwise Multiple Regression Results for Extra Effort with Three Variables

\begin{tabular}{lllllr}
\hline Variable & $\mathrm{B}$ & $S E \mathrm{~B}$ & $\beta$ & \multicolumn{1}{c}{ Sig. } \\
\hline Transformational leadership & 0.14 & 0.02 & 0.59 & 6.30 & $<0.01$ \\
Transactional leadership & 0.13 & 0.08 & 0.16 & 1.59 & 0.12 \\
Laissez-faire leadership & -0.08 & 0.08 & -0.12 & -0.92 & 0.36 \\
Constant & 0.90 & 0.33 & --- & --- & --- \\
Model Summary: $\quad F=39.744, p<.01$ & & & & \\
& $N=77$ & & & & \\
& $R^{2}=.346$ & & & & \\
$\quad$ Adjusted $R^{2}=.338$ & & & & & \\
\end{tabular}

Note. Sig.= Significance $(p$-value $)$. 
Lastly, since transformational leadership was the only variable to display a significant predictive relationship with extra effort, the researcher performed a Baron and Kenny mediation analysis to assess if overall job satisfaction mediated the relationship between perceived transformational leadership and extra effort (Table 4). The researcher conducted a regression with transformational leadership predicting extra effort. The regression of extra effort on transformational leadership was significant, $(F(2,75)=39.74, p<.01)$. The results showed transformational leadership was a significant predictor of extra effort, $(B=0.14)$, indicating the first criterion for mediation was met. The researcher then conducted a regression with transformational leadership predicting overall job satisfaction. The regression of overall job satisfaction on transformational leadership was significant, $(F(2,75)=30.26, p<.01)$, showing transformational leadership was a significant predictor of overall job satisfaction, $(\mathrm{B}=2.54)$. This indicated the second criterion for mediation was met.

Next, the researcher performed a regression with transformational leadership and overall job satisfaction predicting extra effort. The regression of extra effort on transformational leadership and overall job satisfaction was significant, $(F(3,74)=43.03, p<.01)$, which suggested transformational leadership and overall job satisfaction accounted for a significant amount of variance in extra effort. The individual predictors were examined one last time. The results found overall job satisfaction was a significant predictor of extra effort when transformational leadership was included in the model, $(\mathrm{B}=-0.03)$, indicating the third criterion for mediation was satisfied. The results showed transformational leadership was a significant predictor of extra effort when overall job satisfaction was included in the model, $(B=0.21)$, indicating the fourth criterion for mediation was not satisfied. Since criterion 1, 2, and 3 were met, while criteria 4 was not, partial mediation is therefore supported.

Table 4.

Regression Results with Overall Job Satisfaction Mediating the Relationship between Extra Effort and Transformational Leadership

\begin{tabular}{llllll}
\hline Dependent & Independent & B & $S E$ & $t$ & $p$ \\
\hline $\begin{array}{l}\text { Regression 1: } \\
\text { Extra effort }\end{array}$ & Transformational & 0.14 & 0.02 & 6.30 & $<0.01$ \\
$\begin{array}{l}\text { Regression 2: } \\
\text { Job satisfaction }\end{array}$ & Transformational & 2.54 & 0.46 & 5.50 & $<0.01$ \\
$\begin{array}{l}\text { Regression 3: } \\
\text { Extra effort }\end{array}$ & $\begin{array}{l}\text { Transformational } \\
\text { Job satisfaction }\end{array}$ & 0.21 & 0.02 & 9.25 & $<0.01$ \\
& & 0.03 & 0.00 & 5.53 & $<0.01$ \\
\hline
\end{tabular}

\section{Results}

\section{Null Hypothesis 1}

$\mathrm{H} 1_{0}$ : There is no statistically significant predictive relationship between the administrator's transformational leadership style and extra effort. 
The predictor of transformational leadership was statistically significant for the outcome of extra effort $(\beta=0.59, p<0.01)$. Null Hypothesis 1 was rejected. There is sufficient evidence to indicate there is a statistically significant predictive relationship between the perceived use of transformational leadership behaviors and extra effort in the sample.

\section{Null Hypothesis 2}

$\mathrm{H} 2_{0}$ : There is no statistically significant predictive relationship between the administrator's transactional leadership style and extra effort.

The predictor of transactional leadership was not statistically significant to the outcome of extra effort $(p=0.12$ ). Null Hypotheses 2 was not rejected. There is not sufficient evidence to indicate there is a statistically significant predictive relationship between the administrators' perceived transactional leadership behaviors and extra effort in the sample.

\section{Null Hypothesis 3}

$\mathrm{H} 3_{0}$ : There is no statistically significant predictive relationship between the administrator's laissez-faire leadership style and extra effort.

The predictor of overall laissez-faire leadership was not statistically significant to the outcome of extra effort $(p=0.36)$. Null Hypotheses 3 was not rejected. There is not sufficient evidence to indicate there is a statistically significant predictive relationship between the administrators' perceived laissez-faire leadership behaviors and extra effort in the sample.

\section{Null Hypothesis 4}

$\mathrm{H} 4_{0}$ : Overall job satisfaction does not mediate the relationship between any overall style of leadership that displayed a positive predictive relationship with extra effort in this study and extra effort.

The results of a Baron and Kenny mediation found job satisfaction was a partial mediator between the relationship of transformational leadership, the only overall predictor of extra effort in this study, and extra effort. Null Hypotheses 4 was rejected. There is sufficient evidence to indicate job satisfaction partially mediates the relationship between transformational leadership and extra effort.

\section{Discussion}

This study sought to determine if the use of transformational, transactional, and laissezfaire leadership, as perceived by the sample, had a predictive relationship with the perceived extra effort of adjunct faculty who taught online classes. The secondary goal of this study was to determine if job satisfaction had a mediating effect between leadership style and extra effort. The results of stepwise multiple regressions showed perceived transformational leadership behaviors were the only significant predictor of extra effort. These results suggested the use of 
transformational leadership was beneficial to the extra effort put forth by the individuals in the sample, which addressed RQ1.

This study confirmed the findings of Stadelmann (2010), who found perceived transformational leadership behaviors displayed a positive significant predictive relationship with extra effort. This study also confirmed the work of Bass (1990), who found individuals put forth extra effort for leaders who are perceived to exhibit transformational leadership behaviors. Likewise, this research agreed with Bass's (1990) observation that perceived transformational leadership behaviors were more beneficial to organizations than perceived transactional leadership behaviors. Due to the nature of this study, it is unknown how many supervisors were rated by the sample, or if more than one respondent rated an individual supervisor. Regardless, the results suggested the adjunct faculty who taught online classes at the research site preferred their leader's perceived use of transformational leadership. Not only did the perceptions of transformational leadership display a significant positive relationship to extra effort, the results of the bivariate regression used in the mediation analysis showed perceived transformational leadership behaviors were also a positive predictor of overall job satisfaction. This is interesting because the sample rated transformational leadership as the second most used style of leadership $(M=2.85)$ at the research site, behind transactional leadership $(M=2.87)$ which the sample rated as the perceived most used leadership style. Laissez-faire leadership displayed a mean value of 2.79. The sample perceived all three styles of leadership used to a similar extent, even though only perceived transformational leadership behaviors displayed a positive relationship with extra effort. Moreover, the sample indicated ambivalence towards their job satisfaction, and displayed a marginal production of extra effort. This suggests that there may be a disconnect between leadership, or other organizational factors, and adjunct faculty who teach online courses at this university.

Lastly, this study added to academic knowledge concerning the mediating effect of job satisfaction on the relationship between perceived transformational leadership behaviors and extra effort. This study found job satisfaction partially mediated the relationship between perceived transformational leadership behaviors and extra effort, which answered R2. The Reciprocity Theory (Bateman \& Organ, 1983) and Social Exchange Theory (Konovsky \& Pugh, 1994) suggested overall job satisfaction is an important factor in the extra effort of individuals. Given the finding that job satisfaction was a partial mediator between the relationship of the sample's perceptions of their direct superior's use transformational leadership and extra effort, this study agreed with, and adds to the knowledge on these two theories. Again, transactional leadership was perceived by the sample as the most used style of leadership by their superiors ( $M$ $=2.87)$, which might help explain the apathy of the sample towards their job satisfaction $(M=$ $116)$, and their relatively average production of extra effort $(M=2.90)$.

\section{Conclusion and Recommendations for Future Research}

The purpose of this study was to determine if there was a predictive relationship between the perceived use of transformational, transactional, and laissez-faire leadership behaviors by the sample's direct superior and adjunct faculty extra effort, and to investigate the mediating effect of job satisfaction on the relationship between perceived transformational leadership behaviors and extra effort. The results showed perceived transformational leadership behaviors were a 
significant predictor of extra effort. Additionally, the results showed job satisfaction was a partial mediator of the relationship between perceived transformational leadership behaviors and extra effort. These results are significant because they add to the limited amount of research on adjunct faculty who teach in an online environment.

The study sample displayed ambivalence about their job satisfaction and produced only a marginal amount of extra effort. In addition, the sample perceived transactional leadership, which did not display a significant relationship with extra effort, as the leadership style most used by their direct superior. Perceived transformational leadership behaviors were the sole significant predictor of extra effort and displayed a positive relationship with job satisfaction. The high perceived use of transactional leadership might indicate leadership training in transformational leadership is warranted at the research site. Increases in the administration's use of transformational leadership behaviors might increase extra effort and job satisfaction in the sample. The results of this research provided information that may be beneficial in designing leadership development programs intended specifically for leaders who supervise online adjunct faculty.

This study does have limitations. This research study only investigated one school, which limits the conclusions to just one university. While a quantitative study produced data that allowed for inferential statistics, the study is limited by not investigating the motives and insight a qualitative study may have provided; therefore, future research could focus on a qualitative examination of this topic. Demographic questions were not used in this study, which would have allowed for a more thorough investigation of the sample. Future research could investigate if there are differences in leadership perceptions based on age, length of employment, sex, or another demographic factor. The sample for this study was taken from a population of online adjunct faculty from a for-profit university. Similar research on the relationship between leadership and extra effort should also be conducted in the public and private sectors of higher education because the experiences of online adjuncts in these sectors might be different than their counterparts in the for-profit sector. Another recommendation for further research is that additional studies regarding online adjunct experiences be conducted in the for-profit sector of higher education, which have recently been the subject of controversy. Lastly, similar research in different countries is recommended. This research might provide insight into any cultural differences between samples. Future research investigating the perceptions of online adjuncts work experiences is warranted because of the limited amount of research on this population and their importance to the educational system.

Online adjuncts, while a relatively new phenomenon, play an important role in higher education. Understanding their work experiences and perceptions may help universities provide effective support for these often-overlooked employees. Moreover, providing proper support for online adjuncts may, in turn, foster a better educational experience for students. The results of this research should be considered when designing leadership development programs for individuals who supervise online faculty. 


\section{Acknowledgement}

I would like to acknowledge the excellent proof reading skills of my wife, Heather Barnett, without whose support this study would not have been possible.

\section{References}

Allen, I. E., \& Seaman, J. (2016). Online report card - Tracking online education in the United States. Retrieved from Online Learning Consortium: http://onlinelearningsurvey.com/reports/onlinereportcard.pdf

Avolio, B. J., \& Bass, B. M. (2004). Multifactor Leadership Questionnaire: Third Edition Manual and Sampler Set. Menlo Park, PA: Mind Garden Inc.

Avolio, B. J., Bass, B. M., \& Jung, D. I. (1999). Re-examining the components of transformational and transactional leadership using the Multifactor Leadership Questionnaire. Journal of Occupational and Organizational Psychology, 72, 441-462.

Balyer, A. (2012). Transformational leadership behaviors of school principals: A qualitative research based on teachers' perceptions. International Online Journal of Educational Sciences, 4(3), 581-591.

Barnett, D. (2017). Leadership and Job Satisfaction: Adjunct Faculty at a For-Profit University. International Journal of Psychology and Educational Studies, 4(3), 53-63. http://dx.doi.org/10.17220/ijpes.2017.03.006

Baron, R. M., \& Kenny, D. A. (1986). The moderator-mediator variable distinction in social psychological research: Conceptual, strategic, and statistical considerations. Journal of Personality and Social Psychology, 51(), 1173-1182.

Bass, B. M. (1985). Leadership and performance beyond expectations. New York, NY: The Free Press.

Bass, B. M. (1990). From transactional to transformational leadership: Learning to share the vision. Organizational dynamics, 18(3), 19-31.

Bass, B. M. (1997). Does the transactional-transformational leadership paradigm transcend organizational and national boundaries. American Psychologist, 52(2), 130-139.

Bass, B. M., Avolio, B. J., Jung, D. I., \& Berson, Y. (2003). Predicting unit performance by assessing transformational and transactional leadership. Journal of Applied Psychology, 88(2), 207-218. http://dx.doi.org/10.1037.0027-9010.88.2.207

Bass, B. M., \& Avolio, B. J. (1994). Improving organizational effectiveness through transformational leadership. Thousand Oaks, CA: Sage Publications. 
Bass, B. M., \& Riggio, R. E. (2006). Transformational leadership. Mahwah, NJ: Erlbaum.

Bateh, J., \& Heyliger, W. (2014). Academic administrator leadership styles and the impact on faculty job satisfaction. Journal of Leadership Education, 13(3), 34-49. http://dx.doi.org/10.12806/v13/i3/rf3

Bateman, T. S., \& Organ, D. W. (1983). Job satisfaction and the good soldier: The relationship between affect and employee "citizenship". Academy of Management Journal, 4, 587595.

Benton, S., \& Li, D. (2015). Professional development for online adjunct faculty: The Chair's role. The Department Chair, 26(1), 1-3. http://dx.doi.org/10.1002/dch.30027

Burns, J. M. (1978). Leadership. New York, NY: Harper and Row.

Caruth, G. D., \& Caruth, D. L. (2013). Adjunct faculty: Who are these unsung heroes of academe? Current Issues in Education, 16(3), 1-10.

Dailey-Hebert, A., Mandernach, B., Donnelli-Sallee, E., \& Norris, V. (2014). Expectations, motivations, and barriers to professional development: Perspectives from adjunct instructors teaching online. Journal of Faculty Development, 28(1), 67-82.

Datray, J. L., Saxon, D. P., \& Martirosyan, N. M. (2014). Adjunct faculty in developmental education: Best practices, challenges and recommendations. Community College Enterprise, 20(1), 36-49.

Eagan, M. K., Jaeger, A. J., \& Grantham, A. (2015). Supporting the academic majority: Policies and practices related to part-time faculty's job satisfaction. The Journal of Higher Education, 86(3), 448-481. http://dx.doi.org/10.1353/jhe.2015.0012

George, D., \& Mallery, P. (2012). IBM SPSS Statistics 23 step by step: A simple guide and reference (12th ed.). Boston, MA: Pearson.

Gilpin, G. A., Saunders, J., \& Stoddard, C. (2015). Why has for-profit colleges' share of higher education expanded so rapidly? Estimating the responsiveness to labor market changes. Economics of Education Review, 45, 53-63.

http://dx.doi.org/10.1016/j.econedurev.2014.11.004

Halcrow, C., \& Olson, M. R. (2008). Adjunct faculty: Valued resource or cheap labor? Focus on Colleges, Universities, and Schools, 6(1), 1-8.

Kezar, A. (2012). Examining nontenure track faculty perceptions of how departmental policies and practices shape their performance and ability to create student learning at four-year institutions. Research in Higher Education, 54(5), 571-598.

http://dx.doi.org/10.1007/s11162-013-9288-5 
Kezar, A. (2013a). Departmental cultures and non-tenure track faculty: Willingness, capacity, and opportunity to perform at four-year institutions. The Journal of Higher Education, 84(2), 153-188. http://dx.doi.org/10.1353/jhe.2013.0011

Kezar, A. (2013b). Examining non-tenure track faculty perceptions of how departmental policies and practices shape their performance and ability to create student learning at four-year institutions. Research in Higher Education, 54(5), 571-598. http://dx.doi.org/10.1007/s11162-013-9288-5

Konovsky, M. A., \& Pugh, S. D. (1994). Citizenship behavior and social exchange. Academy of Management Journal, 37(3), 656-669.

Locke, E. A., Shaw, K. N., Saari, L. M., \& Latham, G. P. (1981). Goal setting and task performance 1969-1980. Psychological bulletin, 90(1), 125-152. https://doi.org/10.1037/0033-2909.90.1.125

Morris, R. J. (2009). Employee work motivation and discretionary work effort. Unpublished doctoral dissertation. Brisbane Graduate School of Business, Brisbane.

Morton, D. R. (2012). Adjunct faculty embraced: The institution's responsibility. Christian Education Journal, 9(2), 398-407.

Nguni, S., Sleegers, P., \& Denessen, E. (2006). Transformational and transactional leadership on teachers' job satisfaction, organizational commitment, and organizational citizenship behavior in primary schools: The Tanzanian case. School Effectiveness and School Improvement, 17(2), 145-177.

Northouse, P. (2013). Leadership: Theory and practice (6th ed.). Los Angeles, CA: Sage Publications.

Ott, M., \& Cisneros, J. (2015, September 21). Understanding the changing faculty workforce in higher education: A comparison of full-time non-tenure track and tenure line experiences. Education Policy Analysis Archives, 23(90), 1-28. http://dx.doi.org/10.14507/epaa.v23.1934

Philbin, L. P. (1997). Transformational leadership and the secondary school principal. Unpublished doctoral dissertation, Purdue University, West Lafayette, IN.

Rich, T. (2015). A worthy asset: The adjunct faculty and the influences on their job satisfaction. To Improve the Academy, 34(1/2), 156-170. http://dx.doi.org/10.1002/tia2.20010

Spector, P. E. (1997). Job satisfaction survey, JSS page.

Stadelmann, C. (2010). Swiss armed forces militia system: Effect of transformational leadership on subordinates' extra effort and the moderating role of command structure. Swiss Journal of Psychology, 92(2), 83-93. 
Thamrin, H. M. (2012). The influence of transformational leadership and organizational commitment on job satisfaction and employee performance. International Journal of Innovation, Management and Technology, 3(5), 566-572.

http://dx.doi.org/10.7763/ijimt.2012.v3.299

Trofino, J. (2003). Power sharing: A transformational strategy for nurse retention, effectiveness, and extra effort. Nursing Leadership Forum, 8(2), 64-71.

Vroom, V. H. (1964). Work and motivation. New York, NY: Wiley.

Webb, A. S., Wong, T. J., \& Hubbal, H. T. (2013). Professional development for adjunct teaching faculty in a research-intensive university: Engagement in scholarly approaches to teaching and learning. International Journal of Teaching \& Learning in Higher Education, 25(2), 231-238.

\section{Author Biography}

Donald E. Barnett, Ed.D., a past Presidential Management Fellow, is a manager for the Social Security Administration. He also serves on several dissertation committees at Grand Canyon University as a Content Expert on leadership, job satisfaction, and motivation. dbarnett6@my.gcu.edu 